\title{
Information Therapy
}

\author{
Ajitha Nancy Rani ${ }^{1}$, V. Hemavathy ${ }^{2}$ \\ Professor Sree Balaji College of Nursing,Bhrath University. \\ Principal \& Professor, Sree Balaji College of Nursing,Bharath University
}

\begin{abstract}
In these days of healthcare reform, there is an increasing need to control the costs of medical care. Preventive medical care can help by providing information to the patient, not only for illnesses, but for prevention and wellness. "Information Therapy" is a new term for supplying patients with health information, enabling them to make informed decisions about their health and care, participate in their own well-being, and thus decrease the utilization of healthcare resources. The formal definition for Information Therapy is presented and the basis for defining it lies in bibliotherapy, patient education, consumer health trends, patient's rights, and the Freedom of Information Act. The parameters and coverage of Information Therapy are discussed, the roles that Information Therapy can play in healthcare are explored, and the dual nature of its goals is presented.
\end{abstract}

Keywords: Information Therapy

\section{Introduction}

In a 1992 article in JAMA, Lindner introduced the phrase "information therapy," concerned the use of the medical library by the public, and she stated that "every scrap of information leading patients in the direction of discovering more about their disease becomes 'information therapy' ".

\section{The Roots of Information Therapy}

\section{- Biblio therapy}

The basis for beginning to define Information Therapy starts with a look at bibliotherapy. The term biblio means book, and therapy is derived from therapies', which means to serve and to help medically Biblio therapy is generally regarded as directed reading with a therapeutic dialogue or interaction between the patient and a facilitator, often librarian, who has received special training. The idea of bibliotherapy goes back to the early Greeks, who recognized the healing value of reading and placed inscriptions over their library entrances that meant "place of healing for the soul." In addition, as early as the 1800s, Dr. Benjamin Rush recommended the Bible as therapeutic reading. Just as reading can have a therapeutic benefit in bibliotherapy, the possession of information can have a therapeutic effect on mental and physical health and well-being in Information Therapy, and its definition should contain some reference to the therapeutic value of information.

\section{- Patient Education}

Another aspect of Information Therapy can be derived from a look at patient education. A 1984 definition by Johnson states that patient education is "designed to assist patients to cope voluntarily with the immediate crisis response to their diagnosis, with long-term adjustments, and with symptoms; to gain needed information about sources of prevention, diagnosis, and care; and to develop needed skills, knowledge, and attitudes to maintain or regain health status The first idea is the provision of information, regardless of whether it is intended simply to inform or whether it is meant to change behavior. The second tenet is that Information Therapy can be centered either on the patient or directed toward the general public. Last, Information
Therapy should not be limited to information directed toward a specific disease, but could also include information of a preventive nature. In this way, the aim of Information Therapy is to increase the knowledge of the general public and to create a sense of responsibility in patients for preserving and maintaining their own wellness.

\section{- Consumer Trends}

The current consumer trends provide another basis for defining Information Therapy an increase in societal pressure for health information as people are shifting from institutional reliance to self-reliance. In order for health conscious consumers to be self-reliant, they must be provided with information. The new Information Age with its information" super highways", should provide consumers with endless access to massive amounts of health information.

\section{The Roles of Information Therapy}

Many terms have been used for the delivery of information to a patient concerning their health: health education, health information, patient education, patient teaching, patient counselling, and now, a new term "Information Therapy". the term "information therapy" appears to be the most descriptive, the richest in possible meanings, and the broadest in scope. Brenda Dervin, a communications specialist, states that information anything a person finds informing. Individuals cope by trying to make sense of their world, and drawing upon resources available, such as what they have heard, read, seen or experienced. If these resources are inadequate, they seek additional information from other sources.

The information may not be acted upon or utilized in any way, but it appears that just having the information provides people with sense of control and power. The information provided may not need to apply to any specific disease or illness, but may be of a general nature or may be information regarding wellness or prevention of a disease. Therefore, the scope of the term Information Therapy is expanded beyond disease specific information, and beyond patient education. The parameters of Information Therapy should include 


\section{International Journal of Science and Research (IJSR) \\ ISSN (Online): 2319-7064}

Index Copernicus Value (2013): 6.14 | Impact Factor (2014): 5.611

disease-specific information targeted toward an individual such as the causes, symptoms, and treatments available for multiple sclerosis; health information on a general topic such as breast cancer or heart disease; or preventive health information targeted to the general public on topics such as smoking cessation, nutrition and vitamins, exercise and wellness issues. Thus, virtually any information dealing in any way with medicine, health, wellness or quality of life that can be informing, increase skills or improve the attitude of a person can be termed Information Therapy. The coverage of Information Therapy, as should be for all information of any nature, is universal. Health care form policy is concerned with universal access to healthcare, and in the same manner, Information Therapy should be accessible to every individual.

The President's Commission on Ethical Practices in Medicine in 1982 has mandated that medical libraries be open to health consumers, and the Medical Library Association's Code of Ethics includes an ethical obligation to advocate access to information for all people. Information Therapy is meant to increase the general public's knowledge concerning health issues, and should help to create a sense of responsibility in them for their own health. In this way, one of the roles of Information Therapy is to provide patients with informational services and support that will provide facts and decision-making assistance, which will empower them to manage their health, illness, acute or chronic disease, life-threatening situations, or a loss. The Plane tree Health Resource Centre, located on the San Francisco campus of California Pacific Medical Center, was founded on the belief that "access to information can empower people and help them to face health and medical challenges people are able to provide more self-care and to accept self-responsibility for their health and well-being. Pingree et al. states that "for people diagnosed with life threatening illnesses, obtaining necessary information, making effective plans and decisions, and Another important role Information Therapy can provide to people is assistance with self-care. Levin defines self-care as "an intentional behaviour that a layperson takes on his or her own behalf, or on behalf of the family, friends, or community to promote health to treat illness. The practice of self-care includes a variety of activities such as: self-diagnosis based on previous experience, seeking advice from friends and family, selfeducation with over-the-counter medicines and home remedies, consulting books and magazines, asking the advice of pharmacists, or consultation with a healthcare professional.

\section{The Goals of Information Therapy}

The idea of information becoming therapy may be anew use of the term therapy. However, various departments in a healthcare setting provide therapy to patients: physical therapy, occupational therapy, speech therapy, etc. Whatever form it takes, the essential purpose of all these departments is to help the patient to resume the normal activities of independent living.

- to provide people with a sense of control;

- to provide coping and disease management skills;

- to improve the capacity to respond;
- to enhance psychological as well as physiological wellbeing.

- to enable people to provide self-care. These goals, centered on the patient, are of a proactive rather than a reactive

\section{The Goals of Information Therapy which Apply Tomedical Care Are:}

- to enhance the doctor-patient relationship by patients being better informed;

- to increase patient question-asking, allowing the doctor to

- provide information therapy;

- to decrease usage of hospital and physician services by people utilizing self care;

- to prevent costly acute and chronic complications of disease by patients' awareness and self responsibility.

\section{Conclusion}

There are several barriers to the widespread use of Information Therapy that must be addressed. These include: the quality of the content of the information ; liability and confidentiality issues; a person's ability to filter large amounts of information and determine its usefulness; a needs assessment as to the usability of Information Therapy, both from the patient's point of view and from the healthcare professional's view; and the cost of provision of Information Therapy, including the possibility of third-party reimbursement. The information superhighways can provide a unique delivery system for Information Therapy.

\section{References}

[1] Lindner, K. (1992) Encourage Information Therapy. Journal of the American Medical Association, 26(19), 2592.

[2] Brown, E. F. (1975) Bibliotherapy and Its Widening Applications. Metuchen, J.:The Scarecrow Press, Inc.p.9.

[3] Stephens, J. W. (1981) A Practical Guide in the Use Implementation Bibliotherapy.

[4] Neck, N. Y.: Todd \& Honeywell, Inc Brown, op.cit.,p. 10. Great

[5] Johnson, J. \& Blumberg, B. (1984) A commentary on cancer patient education. Health Education Quarterly, 10, 7-18 Green, L. (1986) Prevention and Health 